Article

\title{
The Future of Carbon: An Update on Graphene's Dermal, Inhalation, and Gene Toxicity
}

\author{
Nima Moghimian *,+ and Soroush Nazarpour ${ }^{\dagger}$ \\ NanoXplore Inc., Saint-Laurent, QC H4R 2P2, Canada; nazarpour@nanoxplore.ca \\ * Correspondence: moghimian@nanoxplore.ca \\ + These authors contributed equally to this work.
}

Received: 28 July 2020; Accepted: 17 August 2020 ; Published: 19 August 2020

\begin{abstract}
Recent studies on gene, inhalation and dermal toxicity of few-layer graphene have revealed much lower health risk than expected. This could pave the way for graphene as a young member of the nanocarbons family to become the "heir presumptive" to the long-reigning carbon black.
\end{abstract}

Keywords: graphene; health and safety; toxicity; future; regulation; nanocarbon

\section{Nanocarbons and Health Risks}

Carbon in nanoform has been one of the hottest research and development topics in the past two decades. Several revolutionary applications are enabled due to nanocarbon's exceptional properties such as light weight, electrical and thermal conductivity, mechanical strength, EMI-shielding, and UV resistance. However, there has always been a shadow of health and safety concerns for use of nanocarbons in real life. The question is: are all carbonaceous nanomaterials a serious health and safety concern?

Most carbon blacks and fullerenes are nanosized in all the three dimensions; carbon nanotubes and nanofibers in two dimensions. Graphene is the only carbon nanomaterial that is commonly nanosized just in one dimension. Being only a few nanometers or less in thickness but typically $\geq 0.5 \mu \mathrm{m}$ in lateral size is one of the main reasons that it behaves far differently in biological environments compared to carbon nanotubes and carbon blacks. This unique geometry has a great impact on how it behaves, interacts, and even moves as a material. Accordingly, the general assumption that nanoparticles $<100 \mathrm{~nm}$ can enter the cell, nanoparticles $<40 \mathrm{~nm}$ can enter nucleus, and nanoparticles $<35 \mathrm{~nm}$ can pass the blood brain barrier [1] is most likely not applicable for a 2D material with two dimensions significantly larger than $100 \mathrm{~nm}$.

Among various types of graphene-related materials, few-layer (predominantly $\leq 10$ atomic layers) graphene powder has proven to be very effective for many large-volume, industrial applications [2-8]. Although several studies [9-14] have tried to address the toxicological concerns about graphene, most market players, regulators, and potential customers of graphene have been rightfully discussing the need for more research to understand the remaining safety aspects around graphene in human body. So, what took this so long to happen?

Major regulatory agencies, namely European Chemicals Agency (ECHA), United States Environmental Protection Agency (US EPA), and Environment and Climate Change Canada (ECCC) are very specific about the toxicological studies required for certifying a new material for sales in their respective jurisdictions. For instance, in Canada, when a material is not listed on domestic or non-domestic substances list, the ECCC requires the producer or importer to apply for a permit under New Substance Notification (NSN) Schedule 6 to be able to sell the substance above 50 tons/year. Full study reports for acute dermal, inhalation, and gene toxicity are the heart of such applications. To comply with Registration, Evaluation, Authorization and Restriction of Chemicals (REACH) Annex 
VIII, ECHA requires producers or importers who intend to sell more than 10 tonnes/year in Europe to submit full study reports for several toxicological tests including genotoxicity, acute dermal and acute inhalation toxicities. The US EPA also requires similar studies to regulate a new substance to sell for various applications.

One significant barrier to graphene commercialization from a regulatory standpoint has been the cost of such toxicological studies specific to the graphene product that each producer makes. For instance, a single GLP (good laboratory practice) acute inhalation toxicity study that complies with OECD (Organization for Economic Co-operation and Development) 436 guidelines could cost $>\$ 150,000$. In certain cases, the required testing conditions of a study by ECHA are not exactly the same as those required by ECCC or US EPA. That in turn imposes extra costs on a producer who intends to sell in multiple regions. Given other commercialization barriers [15] such as the costs associated with market and application development, product certification costs, and revenue uncertainty, many graphene producers have had no choice but to postpone such studies or rely mostly on existing studies for graphene's so-called "analogues" such as carbon nanotubes or graphite. Such approaches often cause more uncertainty and leave the regulators with even more doubts.

The good news for the graphene market is that a major health and safety regulatory milestone was achieved in 2020. A mass-produced graphene powder was tested for dermal, inhalation, and gene toxicity (in vivo and in vitro chromosomal aberration). For the first time in graphene's history, the studies were fully designed in accordance with OECD guidelines to be compliant with REACH, TSCA and NSN requirements.

The current article provides an overview of the outcome of these toxicity tests, which were performed on a 6-10-layer graphene powder. This article does not aim to review the literature on various graphene materials, nor to examine the relationship between physicochemical characteristics and the health and environmental risks of carbon nanomaterial (see [11-14]). The authors' goal is to underline a significant milestone for regulating mass-produced graphene powder that is typically made by liquid phase exfoliation of natural graphite. The toxicology of mono-layer graphene commonly made by chemical vapor deposition (CVD), graphene oxide, and reduced graphene oxide is beyond the scope of this short communication.

\section{Toxicological Tests and Results}

The first step in evaluating the health and safety risks of graphene, like any other nanoform, is to determine the main routes of exposure. Exposure to nanomaterials in general can occur mainly via inhalation, oral intake, or skin contact. For biomedical applications, exposure via direct injection should also be taken into consideration. As graphene is not currently used as a food ingredient, oral exposure is only likely to occur from accidental intake. Since few-layer graphene sheets usually form fluffy powders, dermal and inhalative exposures are generally accepted to be the most relevant human exposure routes for risk assessment. Genotoxicity tests are usually performed for the most relevant route of exposure, which for graphene powder is inhalation. Table 1 summarizes the gene, dermal, and acute inhalation toxicity studies recently performed on a 6-10 layer graphene powder with predominant primary particle size of $0.5-2 \mu \mathrm{m}$, purity $\geq 97 \%$ and $\sim 1 \mathrm{wt} . \%$ oxygen content. The graphene powder tested in all studies was GrapheneBlack $3 X$, a product of NanoXplore Inc., produced in Canada and tested in Charles River laboratories in Canada and the USA. 
Table 1. List of toxicity tests on graphene cited in this article.

\begin{tabular}{|c|c|c|c|c|c|}
\hline Test & Category & OECD Number & Animal & Results Summary & Ref. \\
\hline $\begin{array}{l}\text { Combined in vivo } \\
\text { Mammalian Erythrocyte } \\
\text { Micronucleus Test and } \\
\text { Alkaline Comet Assay }\end{array}$ & Genotoxicity & $474 \& 489$ & Rat & $\begin{array}{l}\text { No DNA damage at } \\
\text { max respirable dose }\end{array}$ & [16] \\
\hline $\begin{array}{l}\text { in vitro Mammalian } \\
\text { Chromosome Aberration } \\
\text { Test in Human } \\
\text { Peripheral Blood } \\
\text { Lymphocytes }\end{array}$ & Genotoxicity & 473 & - & $\begin{array}{l}\text { No evidence of } \\
\text { genotoxic activity or } \\
\text { chromosome damage; } \\
\text { no cytotoxicity at } \\
\text { max dose }(2 \mathrm{mg} / \mathrm{mL})\end{array}$ & [17] \\
\hline $\begin{array}{l}\text { Dermal Sensitization } \\
\text { Study }\end{array}$ & Dermal & 406 & Guinea Pig & $\begin{array}{l}\text { No skin sensitization } \\
\text { (score } 0 \text { ) after } \\
\text { repeated dosing }\end{array}$ & [18] \\
\hline $\begin{array}{l}\text { Primary Skin Irritation } \\
\text { Study }\end{array}$ & Dermal & 404 & Rabbit & $\begin{array}{l}\text { No skin irritation } \\
\text { (score } 0 \text { ); no signs of } \\
\text { erythema or edema } \\
\text { were observed }\end{array}$ & [19] \\
\hline $\begin{array}{l}\text { Acute Inhalation Toxicity } \\
\text { Study of a Dry Powder } \\
\text { with 14-Day Observation } \\
\text { Period }\end{array}$ & Inhalation & 436 & Albino Rat & $\begin{array}{l}\text { No adverse effect } \\
\text { observed in lung at } \\
\text { max achievable } \\
\text { aerosol concentration }\end{array}$ & [20] \\
\hline
\end{tabular}

\subsection{In Vivo Mammalian Erythrocyte Micronucleus Test and Alkaline Comet Assay}

A GLP combined in vivo mammalian erythrocyte micronucleus test and alkaline comet assay in rat [16] concluded that the tested graphene did not induce formation of micronuclei in polychromatic erythrocytes in the micronucleus test. It also did not show evidence of induction of DNA damage in the lung in the in vivo comet assay, when administered by nose-only inhalation for $240 \mathrm{~min}$ for 3 days to male and female rats up to $1.92 \mathrm{mg} / \mathrm{L}$, the maximum respirable practical dose.

\subsection{In Vitro Mammalian Chromosome Aberration}

A GLP in vitro mammalian chromosome aberration test in human peripheral blood lymphocytes [17] demonstrated that the tested graphene did not show any evidence of genotoxic activity for induction of chromosome damage. Transmission electron microscopy found no clear evidence of cellular uptake of graphene in human lymphocytes after $21 \mathrm{~h}$ exposure, and no cytotoxicity was observed up to $2000 \mu \mathrm{g} / \mathrm{mL}$, indicating very limited capacity for cellular uptake of graphene, if any.

\subsection{Dermal Sensitization Study in Guinea Pigs}

A GLP dermal sensitization study [18] has shown that repeated dermal dosing of $0.25 \mathrm{~g}$ of graphene to male guinea pigs did not induce skin irritation during or after induction phase, and no dermal response was observed after. These results show that graphene is not a skin sensitizer in guinea pigs.

\subsection{Primary Skin Irritation Study In Rabbits}

A GLP study [19] dedicated to single dermal dosing of $0.5 \mathrm{~g}$ of graphene to male albino rabbits resulted in no skin irritation during 7 days of observation. Graphene was administered dermally once to a $2 \times 3 \mathrm{~cm}^{2}$ area to 3 albino male rabbits for $4 \mathrm{~h}$. The report concluded that single dermal exposure to graphene had no effect on mortality, clinical observations, dermal scoring, or body weights. There were no erythema or edema observations at any time point following dermal exposure to 
graphene. Therefore, single dermal dosing of $0.5 \mathrm{~g}$ of graphene to male albino rabbits resulted in no skin irritation (score 0 ) during the study.

\subsection{Acute Inhalation Toxicity}

A GLP acute inhalation toxicity study [20] of graphene dry powder in the albino rat with 14-day observation period has shown that administration of graphene by nose-only inhalation in male and female rats at achieved aerosol concentration of 0.88 and $1.99 \mathrm{mg} / \mathrm{L}$ when given as a single dose was well tolerated. Given the lack of any adverse finding at any dose, the no-observed-adverse-effect-level (NOAEL) was considered to be $1.99 \mathrm{mg} / \mathrm{L}$ (the maximum achieved aerosol concentration feasible).

\section{Significance of the Results}

The tested graphene has shown no adverse effect to animal skin and lung. But the most significant outcome of these tests is the fact that no gene mutation or DNA damage was observed for graphene in the in vivo or in vitro genotoxicity tests via inhalation. Conversely, inhalation exposure to carbon black is reported [21] to cause mutational changes in the hprt gene in alveolar epithelial cells in rat. This is considered to underly the development of animal lung adenomas and carcinomas. Carbon blacks are predominantly produced by incomplete combustion of hydrocarbons (mainly oil and gas) that not only results in production of greenhouse gases but also generates considerable amounts of polycyclic aromatic hydrocarbons (PAHs). PAHs are linked to skin, lung, bladder, liver, and stomach cancers in well-established animal model studies [22]. PAHs are not present in the tested graphene as the production method does not involve heating at very high temperatures.

\section{Regulation and Future of Graphene}

Graphene is registered in REACH under EC number 801-282-5 and CAS number 1034343-98-0. The EC number distinguishes graphene from graphene oxide (EC 947-768-1) and reduced graphene oxide (EC 922-453-1). Based on the Commission Recommendation of October 18, 2011 on the definition of nanomaterial $(2011 / 696 / \mathrm{EU})$ a nanoform is a form of a natural or manufactured substance containing particles, in an unbound state or as an aggregate or as an agglomerate and where for $50 \%$ or more of the particles in the number size distribution, one or more external dimension is in the size range $1 \mathrm{~nm}$ to $100 \mathrm{~nm}$. In addition to ECHA, the ECCC and US EPA also consider graphene a nanoform due to the fact that its thickness is below $100 \mathrm{~nm}$. The "nano" tag almost always translates to increased health and safety scrutiny by regulators.

Regardless of how great the technical performance of a material is or how low its price goes, industrial adoption will not happen unless the material is regulated. Regulation in turn will not happen until major toxicological study reports become available to the regulatory agencies.

In the early years of graphene mass production, several manufacturers took the approach of presenting graphene as a graphite or an analogue to graphite. The toxicological profile of graphite is already well-known [23] but there was a huge gap between graphite with $>\sim 1000$ carbon layers as defined by its REACH registration dossier, and graphene with $<10$ carbon layers. This approach was never convincing due to the major differences in particle size and geometry, defects, surface area, oxygen content and impurities. In 2020, for the first time, regulators have received study reports on a graphene powder. This marks a major milestone for graphene's market adoption for industrial use.

Graphene has been on track to deliver on its promises as a revolutionary material [24] and is leading the race to become the next big carbon material for use in everyday life. With the growing environmental and sustainability concerns over carbon black's ties with the fossil fuel industry, and health risks [25] associated with its use as a jet black pigment, the need for a safer and more sustainable alternative is becoming more and more critical: A carbon material that can resist damaging UV radiation, conduct electricity, dissipate heat, shield against electromagnetic noise, improve barrier and mechanical properties and, most importantly, is safe. It seems more likely than ever that the future will not be as jet black as today; but more so graphene black. 
Author Contributions: Writing—review and editing: N.M. and S.N. All authors contribute this article. All authors have read and agreed to the published version of the manuscript.

Funding: This research received no external funding.

Acknowledgments: The authors are thankful to Heather Armstrong for her immensely helpful feedback and comments.

Conflicts of Interest: The authors are employees and shareholders of NanoXplore Inc.

\section{References}

1. Jennifer, M.; Maciej, W. Nanoparticle technology as a double-edged sword: Cytotoxic, genotoxic and epigenetic effects on living cells. J. Biomater. Nanobiotechnol. 2013, 4, 26984. [CrossRef]

2. Zhu, Y.; Ji, H.; Cheng, H.M.; Ruoff, R.S. Mass production and industrial applications of graphene materials. Natl. Sci. Rev. 2018, 5, 90-101. [CrossRef]

3. Barkan, T. Graphene: The hype versus commercial reality. Nat. Nanotechnol. 2019, 14, 904-906.

4. Wang, J.; Zhao, C.; Mark, L.H.; Wang, X.; Li, R.; Moghimian, N.; Hamidinejad, M.; Park, C.B. Facilitating Supercritical $\mathrm{CO}_{2}$ Assisted Exfoliation of Graphene Nanoplatelets with the Polymer Matrix. Chem. Eng. J. 2020, 394, 124930. [CrossRef]

5. Moghimian, N.; Saeidlou, S.; Lentzakis, H.; Rosi, G.F.; Song, N.; David, É. Electrical conductivity of commercial graphene polyethylene nanocomposites. In Proceedings of the 2017 IEEE 17th International Conference on Nanotechnology (IEEE-NANO), Pittsburgh, PA, USA, 25-28 July 2017; pp. 757-761.

6. Hamidinejad, M.; Zhao, B.; Zandieh, A.; Moghimian, N.; Filleter, T.; Park, C.B. Enhanced electrical and electromagnetic interference shielding properties of polymer-graphene nanoplatelet composites fabricated via supercritical-fluid treatment and physical foaming. ACS Appl. Mater. Interfaces 2018, 10, 30752-30761. [CrossRef]

7. Hamidinejad, M.; Zhao, B.; Chu, R.K.; Moghimian, N.; Naguib, H.E.; Filleter, T.; Park, C.B. Ultralight microcellular polymer-graphene nanoplatelet foams with enhanced dielectric performance. ACS Appl. Mater. Interfaces 2018, 10, 19987-19998. [CrossRef] [PubMed]

8. Kurusu, R.S.; Helal, E.; Moghimian, N.; David, E.; Demarquette, N. The role of selectively located commercial graphene nanoplatelets in the electrical properties, morphology, and stability of EVA/LLDPE blends. Macromol. Mater. Eng. 2018, 303, 1800187. [CrossRef]

9. Li, Y.; Yuan, H.; Von Dem Bussche, A.; Creighton, M.; Hurt, R.H.; Kane, A.B.; Gao, H. Graphene microsheets enter cells through spontaneous membrane penetration at edge asperities and corner sites. Proc. Natl. Acad. Sci. USA 2013, 110, 12295-12300. [CrossRef] [PubMed]

10. Jachak, A.C.; Creighton, M.; Qiu, Y.; Kane, A.B.; Hurt, R.H. Biological interactions and safety of graphene materials. MRS Bull. 2012, 37, 1307-1313. [CrossRef] [PubMed]

11. Fadeel, B.; Bussy, C.; Merino, S.; Vázquez, E.; Flahaut, E.; Mouchet, F.; Evariste, L.; Gauthier, L.; Koivisto, A.J.; Vogel, U.; et al. Safety assessment of graphene-based materials: Focus on human health and the environment. ACS Nano 2018, 12, 10582-10620. [CrossRef] [PubMed]

12. Bussy, C.; Ali-Boucetta, H.; Kostarelos, K. Safety considerations for graphene: Lessons learnt from carbon nanotubes. Acc. Chem. Res. 2013, 46, 692-701. [CrossRef] [PubMed]

13. Lalwani, G.; D'Agati, M.; Khan, A.M.; Sitharaman, B. Toxicology of graphene-based nanomaterials. Adv. Drug Deliv. Rev. 2016, 105, 109-144. [CrossRef] [PubMed]

14. Zaytseva, O.; Neumann, G. Carbon nanomaterials: Production, impact on plant development, agricultural and environmental applications. Chem. Biol. Technol. Agric. 2016, 3, 17. [CrossRef]

15. Maine, E.; Seegopaul, P. Accelerating advanced-materials commercialization. Nat. Mater. 2016, 15, 487-491. [CrossRef] [PubMed]

16. Charles River Laboratories Montreal ULC; Senneville Site (CR-MTL). GrapheneBlack 3X: A GLP Combined In Vivo Mammalian Erythrocyte Micronucleus Test and Alkaline Comet Assay in Rat, Sponsored by NanoXplore. 2020.

17. Charles River Laboratories Montreal ULC. GrapheneBlack 3X: A GLP In Vitro Mammalian Chromosome Aberration Test in Human Peripheral Blood Lymphocytes, Sponsored by NanoXplore. 2020.

18. Citoxlab USA, Charles River. Graphene: A GLP Dermal Sensitization Study in Guinea Pigs, Sponsored by NanoXplore. 2020 
19. Citoxlab USA, Charles River. Graphene: A GLP Primary Skin Irritation Study in Rabbits; Sponsored by NanoXplore; 2020.

20. Charles River Laboratories Montreal ULC; Senneville Site (CR-MTL). A GLP Acute Inhalation Toxicity Study of a Dry Powder in the Albino Rat with 14-Day Observation Period, Sponsored by NanoXplore. 2020.

21. Driscoll, K.E.; Deyo, L.C.; Carter, J.M.; Howard, B.W.; Hassenbein, D.G.; Bertram, T.A. Effects of particle exposure and particle-elicited inflammatory cells on mutation in rat alveolar epithelial cells. Carcinogenesis 1997, 18, 423-430. [CrossRef] [PubMed]

22. Boström, C.E.; Gerde, P.; Hanberg, A.; Jernström, B.; Johansson, C.; Kyrklund, T.; Rannug, A.; Törnqvist, M.; Victorin, K.; Westerholm, R. Cancer risk assessment, indicators, and guidelines for polycyclic aromatic hydrocarbons in the ambient air. Environ. Health Perspect. 2002, 110, 451-488. [PubMed]

23. Graphite Registration Dossier-ECHA. Available online: https://echa.europa.eu/registration-dossier/-/ registered-dossier/16080 (accessed on 11 August 2020).

24. Reiss, T.; Hjelt, K.; Ferrari, A. Graphene is on track to deliver on its promises. Nat. Nanotechnol. 2019, 14, 907-910. [PubMed]

25. Hodgson, J.; Jones, R. A mortality study of carbon black workers employed at five United Kingdom factories between 1947 and 1980. Arch. Environ. Health Int. J. 1985, 40, 261-268. [CrossRef] [PubMed]

(C) 2020 by the authors. Licensee MDPI, Basel, Switzerland. This article is an open access article distributed under the terms and conditions of the Creative Commons Attribution (CC BY) license (http:/ / creativecommons.org/licenses/by/4.0/). 